\title{
Currículo e ensino-aprendizagem da Matemática na educação ribeirinha no Amapá: um diálogo com a Etnomatemática
}

\author{
Elivaldo Serrão Custódio ${ }^{1}$
}

\begin{abstract}
RESUMO
O presente artigo busca investigar de que maneira o professor da educação básica utiliza do diálogo entre a etnomatemática e o processo de ensino e aprendizagem da matemática em sua prática pedagógica. Acredita-se que ao aplicar a etnomatemática em classe, os alunos conseguem perceber que a matemática tem relação com seu cotidiano, melhorando assim sua aprendizagem. Trata-se de um estudo exploratório quanti-qualitativo, que utilizou a bibliografia, a observação direta e o questionário como forma de investigação. Os resultados apontam que apesar das dificuldades enfrentadas pela escola pesquisada, o docente busca aplicar a etnomatemática com seus discentes, fazendo com que eles se sintam mais valorizados, tornando as aulas mais atrativas, onde também o docente consegue maior participação por parte dos mesmos. Assim, valorizando a realidade cultural dos alunos é possível afirmar que existe um melhor rendimento no processo de ensino e aprendizagem da matemática na educação básica.
\end{abstract}

PALAVRAS-CHAVE: Etnomatemática. Saberes locais. Currículo. Ensino e aprendizagem.

Curriculum and teaching learning of mathematics in river education in Amapá: a dialogue with ethnomatematics

\footnotetext{
${ }^{1}$ Doutor em Teologia. Universidade Federal do Amapá (UNIFAP), Santana, Amapá, Brasil. https://orcid.org/00000002-2947-5347.elivaldo.pa@hotmail.com.
} 


\begin{abstract}
This article seeks to investigate how the teacher of basic education uses the dialogue between ethnomathematics and the process of teaching and learning mathematics in his pedagogical practice. It is believed that when applying ethnomathematics in class, students are able to perceive that mathematics is related to their daily lives, thus improving their learning. It is a quantitative and qualitative exploratory study, which used the bibliography, direct observation and the questionnaire as a form of investigation. The results show that despite the difficulties faced by the researched school, the teacher seeks to apply ethnomathematics with his students, making them feel more valued, making the classes more attractive, where the teacher also gets greater participation from them. Thus, valuing the cultural reality of the students, it is possible to affirm that there is a better performance in the process of teaching and learning mathematics in basic education.
\end{abstract}

KEYWORDS: Ethnomathematics. Local knowledge. Curriculum. Teaching and learning.

Currículo y enseñanza de las matemáticas en la educación en el río en Amapá: un diálogo con la etnomatemática

\title{
RESUMEN
}

Este artículo busca investigar cómo el profesor de educación básica utiliza el diálogo entre etnomatemáticas y el proceso de enseñanza y aprendizaje de las matemáticas en su práctica pedagógica. Se cree que al aplicar la etnomatemática en clase, los estudiantes pueden percibir que las matemáticas están relacionadas con su vida diaria, mejorando así su aprendizaje. Es un estudio exploratorio cuantitativo y cualitativo, que utilizó la bibliografía, la observación directa y el cuestionario como forma de investigación. Los resultados muestran que a pesar de las dificultades que enfrenta la escuela investigada, el maestro busca aplicar la etnomatemática con sus alumnos, haciéndolos sentir más valorados, haciendo que las clases sean más atractivas, donde el maestro también obtiene una mayor participación de ellos. Así, valorando la realidad cultural de los estudiantes, es posible afirmar que hay un mejor desempeño en el proceso de enseñanza y aprendizaje de las matemáticas en la educación básica. 
PALABRAS CLAVE: Etnomatemática Conocimiento local. Plan de estudios Enseñanza y aprendizaje.

\section{Introdução}

Os conhecimentos etnomatemáticos utilizados pelos ribeirinhos, possuem benefícios matemáticos que podem ser aplicados em diversas áreas, ou até mesmo tornando os serviços utilizados por eles mais prático e eficaz. A proposta de trabalho numa linha de etnomatemática tem como objetivo valorizar a matemática de diferentes grupos culturais. Propõe-se uma maior valorização dos conceitos matemáticos informais construídos pelas pessoas através de suas experiências, fora de um contexto de matemática mais aprofundado, ou seja, um contexto de conhecimentos prévios da matemática. A etnomatemática procura entender não só o conhecimento matemático dominante e oficial, isto é, o que é ensinado nas escolas, mas também o saber e o fazer matemático das culturas e tradições de cada sociedade.

A etnomatemática é um elo entre as tradições e a modernidade, tendo como origem entender o fazer e o saber matemático, e se desenvolve a partir da prática do conhecimento tradicional que resulta das culturas de cada grupo social. Usar a cultura dos povos é essencial no desenvolvimento do conhecimento, envolvendo o que constitui o domínio das chamadas ciências da cognição, da epistemologia, da sociedade, da história, e da multiplicação do conhecimento, o que inclui a educação, não só a estudantil, como a educação do campo, a educação ribeirinha, desenvolvendo assim a cultura de cada um.

Diante deste contexto, o tema proposto envolve o uso da etnomatemática e sua relação com a matemática. A motivação para essa pesquisa partiu do interesse de minha parte juntamente com o interesse dos meus orientandos (Andrey de Menezes Farias Lopes, Driely Thayla de Menezes Farias Lopes, Jeovana da Silva Baia, Alberto Ribeiro dos Santos 
Júnior, Roney Cardoso Facundes e Thalisson Azevedo Gomes) do Curso de Licenciatura Plena em Matemática da Faculdade Madre Tereza em Santana$\mathrm{AP}$, em querer utilizar a etnomatemática e a cultura local ribeirinha de modo que a mesma pudesse colaborar para o aprendizado dos discentes da educação básica.

O recorte da pesquisa foca nos alunos do $7^{\circ}$ ano do ensino fundamental da Escola Estadual Levindo Alves dos Santos do Distrito da Ilha de Santana, uma região ribeirinha localizada no município de Santana, estado do Amapá. Com base nesses fundamentos chega-se a seguinte questão: de que forma o professor ensina a matemática em escola ribeirnha e, nesse processo, como acontece o diálogo com a etnomatemática?

A presente pesquisa ocorreu no primeiro semestre de 2019 e foi realizada em quatro etapas: na primeira foi utilizada da pesquisa bibliográfica relacionada a etnomatemática e seus teóricos; na segunda, observação direta na turma do $7^{\circ}$ ano do ensino fundamental da Escola Estadual Levindo Alves dos Santos; na terceira, aplicação de questionário com o professor e os alunos; na quarta, análise e discussão dos resultados da pesquisa.

Partimos do pressuposto que para conhecer os saberes etnomatemáticos dos ribeirinhos é necessário observar e verificar como esses conhecimentos são utilizados e como/onde são aplicados esses métodos matemáticos. Portanto, teremos uma base de como surgiram esses conhecimentos, como se aprimoraram e passaram a serem utilizados de forma prática.

Assim, o presente artigo busca investigar de que maneira o professor da educação básica utiliza do diálogo entre a etnomatemática e o processo de ensino e aprendizagem da matemática em sua prática pedagógica Além disso, busca ainda investigar quais os conhecimentos matemáticos já compreendidos/percebidos pelos discentes através de suas experiências enquanto alunos ribeirinhos e; compreender de que forma a etnomatemática tem contribuído para a prática da vida cotidiana nesta localidade. 
A construção do conhecimento adquirido através da etnomatemática, nos proporcionou maneiras diversas de construir práticas educacionais que possam contribuir com as necessidades dos povos ribeirinhos da Amazônia. A temática cultural nessa discussão tem sua relevância porque proporciona a reflexão sobre as dificuldades/desafios enfrentados por alunos ribeirinhos dentro da sala de aula e a adaptação do processo de ensino e aprendizagem para a realidade local dos mesmos.

\section{Caminhos metodológicos da pesquisa}

Trata-se de um estudo exploratório quanti-qualitativo, que utilizou a bibliografia, a observação direta e o questionário como forma de investigação O locus da pesquisa foram os alunos ribeirinhos do $7^{\circ}$ ano do ensino fundamental da Escola Estadual Levindo Alves dos Santos localizada na ilha de Santana-AP. Neste trabalho buscamos compreender o meio cultural, a forma com a qual o professor repassa/transmite o conhecimento para seus alunos. A coleta de dados foi realizada através de aplicação de questionário para o professor da turma do $7^{\circ}$ ano do ensino fundamental e 15 alunos correspondendo a $100 \%$ do total de matriculados nesta turma.

A finalidade da aplicação do questionário foi compreender por parte do professor, o seu entendimento sobre a etnomatemática, a metodologia aplicada na classe, se existe construção ou manuseio de algum tipo de material na temática da cultura ribeirinha e se há aplicação do conhecimento da matemática envolvendo a cultura local.

Por parte dos alunos, a finalidade da aplicação do questionário foi investigar o entendimento deles quanto a relação da matemática com o seu cotidiano, se é compreensível a forma com a qual a matemática é ensinada, da valorização da cultura na sala de aula e da motivação do ensino da matemática repassado na classe.

Para a investigação dos fatos nos debruçamos nos fundamentos da Análise de Conteúdo a partir da Teoria de Bardin (2011). Segundo a autora, 
a análise de conteúdo vem a ser uma união de métodos de análises das comunicações que visa obter, tanto por objetivos de definição do assunto das mensagens quanto por posicionamentos sistemáticos, indicações que possibilitam a conclusão de saberes relativos às circunstâncias de recepção/produção (aspectos deduzidos) dessas mensagens sendo elas (quantitativas ou não) (BARDIN, 2011, p. 47).

É importante ressaltar que a pesquisa atendeu todos os procedimentos éticos para a execução da pesquisa, conforme a Resolução n. 466/2012 do Conselho Nacional de Saúde.

\section{Contextualização da educação matemática}

A educação matemática surgiu, dentre outros fatores, da falta de renovação do ensino e da prática da matemática e do aperfeiçoamento do aprendizado do professor, cálculos descontextualizados, rigorosidade dos docentes, penalidade para os discentes nas avaliações e foco restrito em decorar fórmulas, dentre outras.

Os métodos tradicionais, que são conhecidos como métodos desatualizados, eram problemas para o patrono da educação matemática, educador e pesquisador matemático Ubiratan D’Ambrósio que nasceu para consertar e/ou aliviar os desprazeres matemáticos.

Percebemos no percurso histórico da educação matemática que o discente era protagonist inativo dos métodos de ensino e somente acolhedor do que se compreendia por aprendizado, isso tudo no modelo tradicional de ensino escolar. Dessa maneira, o docente era inquestionável, continha toda a informação, livre de erros, ou seja, a matemática era focada no docente. $\mathrm{O}$ docente colocava conhecimentos prontos diante do aluno, que era apenas um caixote livre. $\mathrm{Na}$ avaliação era pregado uma direção única que levaria a conclusões das atividades, era - ou inclusive é? - baseando-se em memorizar as fórmulas e soluções de exercícios puramente mecânicos.

No decorrer dos tempos, estes padrões foram alterados e apropriados 
às necessidades do discente com o surgimento do ensino da matemática. Atualmente verificamos que muita coisa mudou, pois o aluno participa ativamente do processo de estruturação do aprendizado, passando a ser sujeito presente, questionador, reflexivo e protagonista.

Embora o professoe não seja mais o único conhecedor de todas as coisas, é um indivíduo fundamental no processo de ensino e aprendizagem. Revendo suas práticas de ensino, o docente teve de se adequar a esse novo ambiente educacional, seguindo uma atual linha investigativa sobre a ação ensino e aprendizagem, reconsiderando a sua condição de professor e dando continuidade à sua formação.

O discente que traz em sua mente uma experiência cultural e um saber de mundo, é um aprendiz vislumbrado pelo ensinamento da matemática. Saberes estes, que têm de ser úteis para os conteúdos curriculares. Assim, desejando desvendar a multiculturalidade do educando e da sociedade em que está introduzido, iniciando sempre de uma investigação e desse modo, dá vida a que D'Ambrósio chama de etnomatemática.

\section{Contextualização da etnomatemática}

Ajudar a identificar e a compreender a matemática de uma cultura, é o objetivo da Etnomatemática que surgiu no ano de 1970. No decorrer da história, para compensar às suas carências de sobrevivência, os povos criaram habilidades próprias de observação e reflexão. Observe este exemplo: de fragmento de pedra, o ser que vivia nas cavernas criou uma faca por primeiro, pois queria expandir suas opções de alimento. Em seguida, produziu uma lança. Então, para conhecer o comprimento de cada material, usou cálculos, para determinar formas, usou geometria, e a respeito da lança, teve de saber a velocidade necessária de arremesso para acertar a presa e também, ficar uma certa distância da presa.

Portanto, um dos propósitos da etnomatemática é identificar, acolher e descobrir. É necessário haver um olhar mais abrangente para o ser humano 
para que a mesma se utilize, além dos fatores culturais, considerando outros pontos, como os históricos e geográficos, gerando assim a interdisciplinaridade. É necessário aceitar os saberes do sujeito para a etnomatemática e, em diversas situações que em determinados problemas há inúmeras maneiras de agir e pensar, assim a criança poderá escolher qual caminho deseja seguir.

A etnomatemática é a arte de lidar e conviver com a realidade natural e sociocultural das pessoas. O Brasil tem uma história cultural muito rica, onde trabalhando a etnomatemática pode elaborar um padrão educacional que envolve seu povo, de uma forma que a matemática deva ser compreendida não apenas como elemento educacional, mais também como um conhecimento histórico-sócio-cultural. A história representa de maneira geral os conhecimentos adquiridos anteriormente por povos que construíram maneiras de se trabalhar através das dificuldades encontradas no dia-a-dia. Todas os diferentes grupos sociais produzem algum conhecimento matemático. A etnomatemática tende a valorizar e entedenter que todo conhecimento e válido e importante.

A etnomatemática defende as ações pedagógicas culturais dos educandos de diferentes grupos sociais. Sendo assim, se tornam mais eficazes de se trabalhar com conceitos matemáticos aprendidos fora da sala de aula. Nessa perspectiva, os conteúdos e conceitos devem ser trabalhados de acordo com a realidade social de cada grupo. Os estudos de atividades fora da sala de aula proporcionam um rico aprendizado prático, que muitas vezes faz falta no entendimento de problemas matemáticos, por isso, o ensino da matemática na perspectiva da etnomatemática contempla o cotidiano, ou seja, tanto a teoria quanto a prática.

\section{Conhecimentos tradicionais dos povos ribeirinhos da Amazônia}

A forma como as comunidades ribeirinhas vivem de frente para o rio e de costa para a floresta, transmite a maneira como as pessoas se adequam ao 
ambiente e os meios impostos para que consigam sobreviver sem utilizar-se de produtos industrializados. A pesca, a caça e a agricultura são a maioria dos meios utilizados para a alimentação dos ribeirinhos na Amazônia.

Os conhecimentos repassados dos povos antigos para as gerações atuais atravessa gerações, o meio em que é feito a medida dos frutos para saber o tanto certo há ser coletado sem a utilização de qualquer recipiente se torna comum para os ribeirinhos, pelo fato de sempre estarem em contato com esse meio de trabalho.

Os conhecimentos que os ribeirinhos da Amazônia possuem não se restringem apenas em coletas e caças. A criatividade e o manejo vai além dos saberes populares, como por exemplo: a criação de transportes marítimos, móveis domésticos, construções de casas, entre outros.

A cultura que é repassada como herança de pai para filho dividisse em dois domínios de saberes: de um lado a tradição seguida de acordo com a cultura do indivíduo, do outro a ciência e a modernidade. A predominância de um domínio sobre o outro e a discrepância entre eles se constitui um dos problemas cruciais do nosso tempo.

A etnomatemática contribuiu para a investigação de atitudes e o desenvolvimento de meios de pensamentos, cujo o alcance e a utilidade ultrapassam o âmbito da respectiva matemática que podem formar no aluno, criando hábitos de averiguação, capacidades de solucionar questões genuínas, proporcionando o desprendimento e confiança para enfrentar e analisar novas situações, além de acrescer outras habilidades pessoais como a originalidade, o estudante está empregando um grupo de métodos e técnicas da matemática no caráter instrumental, no percurso de modelo até o resultado final.

Percebemos no dia a adia da educação escolar que a maior parte dos educandos aprendem de diversos modos fora do ambiente educacional. No entanto, este conhecimento é disperso, fragmentado e muitas vezes não eficaz. Levando em consideração a realidade dos ribeirinhos da Amazônia, acreditase que o professor deve respeitar o conhecimento conquistado no cotidiano dos alunos, pois eles chegam à escola com certo nível de conhecimento adquirido 
pela sua história de vida e experiências que não podem ser ignoradas.

Desse modo, visa-se a não exclusão dos alunos das classes menos privilegiadas, ou seja, respeita-se a realidade dos alunos criando as oportunidades para que todos aprendam.

\section{A importância de valorizar a realidade dos alunos amazônidas}

A etnomatemática vem para cumprir o papel da importância que é o professor valorizar a realidade dos discentes, mostrando por exemplo, que mesmo comunidades não alfabetizadas, possuem informações matemáticas e que essas informações não deixam de ter relevância só por não serem ensinadas na escola, elas apenas são diferentes.

A realidade do aluno não pode ser desprezada pela escola. As instituições escolares devem valorizar o contexto no processo de ensino e aprendizagem. É um vínculo que facilita o início do conhecimento escolar e a competência matemática adquirido no ambiente cultural do mesmo. Essa competência acaba por não ser empenhada em classe, justo pela supervalorização depositada ao raciocínio culto, pelo moderno processo de ensino, gerando assim, uma vinculação de desconforto junto a matemática, por amputar, os princípios socioculturais do discente (SOUZA; CARDOSO, 2009).

A etnomatemática não sugere que os livros educativos parem de ser utilizados, ela não desconsidera a matemática científica. O propósito é analisar a matemática numa linguagem mais aproximada da vida do educando, ou seja, valorizando os saberes já adquiridos em sociedade.

Desta forma, tornar o ensinamento matemático acessível a todos, ajudar a solucionar problemas do cotidiano, reconhecendo que a matemática proporciona ferramentas eficientes para compreender e exercer no mundo que nos rodeia, são os pontos positivos que esperamos alcançar.

Os professores devem saber da grande importância que a etnomatemática têm no desenvolvimento sociocultural, psicológico e 
intelectual do aluno. Assim, é preciso ajudá-los não só a solucionar problemas matemáticos, mas ajudá-los a resolver problemas do cotidiano a fim de atinjirem uma realização pessoal e a adquirem um desenvolvimento pleno. Preparar o aluno para a vida é o principal objetivo da educação básica. Conforme exposto nos Parâmetros Curriculares Nacionais (PCN) de matemática (BRASIL, 2001, p. 37):

Numa reflexão sobre o ensino da matemática é de fundamental importância ao professor: [...] conhecer a história de vida dos alunos, sua vivência de aprendizagens fundamentais, seus conhecimentos informais sobre um dado assunto, suas condições sociológicas, psicológicas e culturais.

Dessa maneira, é preciso que os professores busquem atualizar-se com o objetivo de construir um futuro que seja melhor que o presente, pois é impossível falar de educação sem falar de futuro, tecnologia. E ciência e a matemática tem grande relevância nessa tarefa, já que as mesmas tem raízes profundas nos sistemas culturais, como argumenta D’Ambrósio (1998, p. 25) quando afirma que "sem dúvida, o futuro está impregnado da tecnologia e ciência, para o bem ou para o mal. A matemática está na raiz da tecnologia e da ciência”.

Os estudos sobre a Etnomatemática propõem aos professores conhecer a realidade dos seus alunos. É preciso conhecer o âmbito sociocultural em que vivem, através da troca de experiências, de modo que os professores possam ganhar a confiança das pessoas que fazem parte desse contexto e poder desenvolver com harmonia a prática docente. $\mathrm{Na}$ escola, os alunos devem sentir-se motivados para o estudo, principalmente quando se aborda fatos da realidade deles, e isso é fundamental para manter uma relação de confiança entre docente e discente.

\section{Prática e importância do ensino da etnomatemática: algumas considerações}


A partir dos anos de 1960 a 1970 o ensino da matemática vem tendo diversas modificações e atualizações, tendo a etnomatemática como atividade pedagógica alternativa. Esta ação pedagógica, analisa o âmbito sociocultural dos educandos, valorizando as informações prévias dos mesmos na estruturação de significados definido pela capacidade natural da experiência individual, aproximando o conteúdo matemático junto à realidade. Conforme os PCN (BRASIL, 2001, p. 23) de matemática:

[...] do ponto de vista educacional, procura entender os processos de pensamento, os modos de explicar, de entender e de atuar na realidade, dentro do contexto cultural de cada indivíduo. A Etnomatemática procura partir da realidade e chegar à ação pedagógica de maneira natural, mediante um enfoque cognitivo com forte fundamentação cultural.

Podemos dizer que a etnomatemática é uma linha de pesquisa que caminha junto com a vida escolar. A matemática é uma disciplina muito visada no sistema educacional pelo fato de ser universal e pelo fato de caracterizar a própria espécie humana pelo raciocínio; e isso possibilita ao discente a capacidade de resolver problemas com acontecimentos reais, ou seja, a matemática é extremamente útil para a vida.

Essa prática docente não se restringe apenas com a resolução de situações-problemas, mas busca a compreensão de como os sujeitos usam sistemas matemáticos diferentes para resolver problemas do cotidiano. Como afirma D’Ambrósio (1998, p. 16):

Isso significa desenvolver a capacidade do aluno para manejar situações reais, que apresentam a cada momento de maneiras distintas. Não se obtém isso com simples capacidade de fazer contas nem mesmo com a habilidade de solucionar problemas que são apresentados aos alunos de maneira adrede preparada. 
A etnomatemática vem nos incentivar a entender e perceber a realidade dos nossos discentes, propiciando aos mesmos a chance de valorizar suas realidades podendo, assim, através da criatividade, criar estratégias para transformá-las a partir do instante que as conheçam e as aceitam, acreditando que possam construir sua própria história.

A matemática é um meio essencial na solução de problemas do mundo em que vivemos. Nela são desenvolvidas estruturas abstratas baseadas em modelos concretos e raciocínios puramente formais que permitem concluir sobre a possibilidade, ou não, da existência de certos padrões e suas propriedades no modelo original, podendo identificar os dados relevantes e elaborar estratégias numa situação-problema, para buscar possíveis resoluções. Como comenta D’Ambrósio (1998, p. 39):

A busca natural de uma explicação para realidade na qual o indivíduo está inserido leva-o a essa compulsão para saber, para esclarecer a ordem cósmica e natural, e para desvendar as forças que permanentemente o informam sobre o curso da realidade, impactando-o em direção a uma ação incessante.

Desse modo, a etnomatemática tem como foco incentivar os alunos a tornarem-se cidadãos críticos e participativos, podendo inserir-se no mercado de trabalho sendo capazes de assimilar informações rápidas e solucionar problemas em equipe, acreditando que a evolução é um processo dialético.

É essencial que as escolas tenham analogias com entidades de ensino e essa analogia seja diferente em razão da qualidade do ambiente social e da freguesia, diferenciação que não quer dizer fragmentação, mas consideração ao conhecimento dos discentes no que repercute às desigualdades do ponto de saída no qual se deparam.

A diversidade existente na sala é rica em situações-problema, mas nem sempre é explorada como um potencial contextualizador do estudo matemático já sistematizado, a fim de que proporcione aos alunos uma 
aprendizagem significativa, procurando a valorização da pluralidade sociocultural. Conforme a Lei de Diretrizes e Bases da Educação (BRASIL, 2007) temos, no artigo 28, a seguinte estrutura:

$\mathrm{Na}$ oferta de educação básica para a população da zona rural, os sistemas de ensino promoverão as adaptações necessárias a sua adequação as peculiaridades da vida rural e de cada região, especialmente: I - conteúdos curriculares e metodologias apropriadas ás reais necessidades e interesses dos alunos da zona rural; II - organização escolar própria, incluindo adequação do calendário escolar as fases do ciclo agrícola e as condições climáticas; III - adequação à natureza do trabalho na zona rural.

Nota-se que conforme as normas da nova Lei de Diretrizes e Bases da Educação os conteúdos matemáticos têm que ser organizados conforme a peculiaridade da vivência do aluno, exemplificando-os de forma clara e objetiva. Deste modo, a escola e todos os seus membros, têm que elaborar juntos o projeto político pedagógico de modo que os alunos tenham oportunidades de aprender independentemente do lugar em que vivem.

O conhecimento é enriquecido por meio da comunicação entre indivíduos do mesmo processo. Ninguém tem a mesma capacidade de processar informações, mesmo que estejam num mesmo meio, constituindo assim a cultura dessa comunidade ou desse grupo social, ajudando os indivíduos a viverem em sociedade; o conhecimento resulta de uma resposta a certa situação.

A matemática é parte integrante no desenvolvimento socioeconômico e político da sociedade. Dessa forma, a etnomatemática também pode ser vista como uma prática social, pelo fato de valorizar a cultura de cada indivíduo. No entanto, nosso sistema educacional brasileiro - em especial a prática das teóricas aplicadas em sala de aula - tem dificuldade em valorizar a própria cultura, pois é aplicado de forma tímida na maioria de nossas escolas, o que em outros países já acontece de forma substancial. 
A sociedade é digna de sua própria cultura, seus valores, seu próprio modelo econômico, político e educacional, assim como os alunos ribeirinhos, têm que aprender a valorizar suas origens, sua comunidade, seu meio social para que possam usar sua criatividade para melhoria de sua própria realidade. Como relata D’Ambrósio (2004, p. 18):

Todo conhecimento é resultado de um longo processo cumulativo de geração, de organização intelectual, de organização social, naturalmente não-dicotômicos entre si. Esses estados são normalmente de estudos nas chamadas teorias da cognição, epistemologia, história e sociologia, e educação e política.

O ensino da matemática vem passando nos últimos anos por sérias transformações por conta da chamada diversidade cultural. A maneira com que interagimos com indivíduos do mesmo meio cultural ou de meios culturais distintos, faz surgir às trocas de experiências e então ocorre o conhecimento e condições para melhoria de cada grupo cultural. Por isso é importante as relações interculturais e intraculturais entre as sociedades, em especial na educação escolar. Segundo D’Ambrósio (2004, p. 28):

[...] lamentavelmente, ainda há relutância no reconhecimento das relações intraculturais na educação. Ainda se insiste em colocar crianças em séries de acordo com a mesma idade, em oferecer na mesma série o mesmo currículo, chegando até ao absurdo de se propor currículos nacionais.

O conhecimento matemático se constrói como um processo histórico, em relação às condições sociais, políticas e econômicas de um determinado grupo. Portanto, o conhecimento não é apenas resultado de anos de estudo, é resultado da troca de experiências entre indivíduos de um mesmo e/ou de diferentes contextos históricos, das necessidades cotidianas de desenvolver uma inteligência prática que permite solucionar problemas, tomar decisões e 
interagir numa sociedade com diversas culturas como é o caso da cultura ribeirinha dos povos da Amazônia.

A criação do conhecimento matemático, dá-se pela necessidade, do homem atuar em seu mundo. Como afirma Rosa Neto (1998, p. 43), referenciando Vygotsky:

O aprendizado das crianças começa muito antes de elas frequentarem a escola. Qualquer situação de aprendizado com a qual a criança se defronta na escola tem sempre uma história prévia”. Por isso é importante uma boa experiência de vida.

É preciso compreender a construção do conhecimento matemático como um processo histórico, em estreita relação com as condições sociais, políticas e econômicas de um determinado grupo. Portanto, o conhecimento das crianças depende de diversos fatores, a família e meio social em que vivem com certeza são importantes para o desenvolvimento intelectual de cada um. Os professores precisam aproveitar o conhecimento adquirido pelo aluno através de suas experiências cotidianas e incentivá-los a acreditar que têm um papel ativo na criação do conhecimento cultural e social.

Como as reformas no ensino da matemática surge a ideia de contextualização que entrou em pauta com o início da nova Lei de Diretrizes e Bases da Educação Nacional, que orienta os professores e a escola da importância da valorização da matemática para o uso no cotidiano dos alunos, onde afirma que os conteúdos têm que ser contextualizados, ou seja, organizados de forma significativa e globalizada, colocando-os mais próximos do universo cultural que o discente vive. De acordo com os PCN de matemática (BRASIL, 2001, p. 39):

[...] para que sejam transferíveis a novas situações e generalizados, os conhecimentos devem ser descontextualizados, para serem contextualizados novamente em outras situações. Mesmo no ensino fundamental, espera-se que o conhecimento aprendido não fique 
indissoluvelmente vinculado a um contexto concreto e único, mas que possa ser generalizado, transferido a outros contextos.

A proposta é interessante e chama a atenção para a necessidade de planejarmos o conteúdo matemático contextualizando sua origem, a fim de que haja um aprendizado significativo, demonstrando qual realmente são seus valores, ou seja, dar significado ao conteúdo matemático permitindo que os alunos apresentem uma postura crítica e participativa.

Embora tenhamos que valorizar o cotidiano do aluno, o saber não deve se reduzir somente ao saber cotidiano. A escola e demais participantes do processo educativo devem aprimorar esse saber para que os discentes sejam preparados para solucionar situações-problemas do cotidiano de maneira ágil e eficiente, sempre acreditando que são capazes e agentes ativos no espaço em que vivem. Todavia, é preciso trabalhar com um contexto que tenha significado para o discente onde o mesmo possa desempenhar um papel de protagonista na construção do conhecimento.

Acredita-se que o discente deva desenvolver no processo de ensino e aprendizagem não só a intelectualidade, mas também a participação coletiva, retirando o aluno da condição de mero espectador passivo, estabelecendo assim, conexões/relações substanciais e não arbitrárias entre os conteúdos escolares e os conhecimentos previamente construídos por eles.

Levar o discente a superar o distanciamento entre os conteúdos estudados e suas experiências cotidianas, estabelecendo relações entre os tópicos estudados e os vividos na prática, trazendo portanto, referências que podem ser de natureza histórica, cultural ou social, ou mesmo dentro da própria matemática.

\section{Resultados e discussões da pesquisa de campo}

A pesquisa de campo foi realizada a partir da observação direta em sala de aula com alunos do $7^{\circ}$ ano do ensino fundamental da Escola Estadual 
Levindo Alves dos Santos na Ilha de Santana, município de Santana-AP.

A pesquisa ocorreu durante o mês de abril de 2019 sendo que no primeiro contato com a turma foi exposto o objetivo do trabalho e a necessidade de colaboração e participação da turma para o bom andamento da pesquisa. Observou-se nesse primeiro contato que os discentes são bem interessados, participando de forma ativa de todas as atividades e obedecendo ao comando do docente.

No segundo momento foi aplicado um questionário para o docente e também para quinze alunos da turma, sendo sete do sexo feminino e oito do sexo masculino. É pertinente ressalar que ambos responderam ao questionário atendendo as nossas expectativas quanto a utilização da etnomatemática por parte do professor.

No questionário, composto de oito questões para os discentes e cinco para o docente, sendo todas fechadas, optou-se por não exigir a identificação dos alunos e nem a do professor, como forma de manter a integridade dos mesmos e de deixá-los à vontade para que pudessem responder as questões relacionadas a etnomatemática na sala de aula. Destaca-se que o questionário atendeu todos os procedimentos éticos para a execução da pesquisa, conforme a Resolução n. 466/2012 do Conselho Nacional de Saúde.

As questões foram elaboradas visando identificar a metodologia aplicada pelo professor, entendimento da etnomatemática e se utiliza deste conhecimento em suas aulas. Já para os discentes, se entendem a relação da matemática com o seu cotidiano, se eles conseguem compreender a forma que a matemática é ensinada na sala de aula, se o professor relaciona os assuntos e atividades ao seu cotidiano, se os mesmos tem dificuldades para entender a matemática ensinada na classe e se eles se sentem motivados pela forma como o conhecimento matemático lhe é repassado.

Com base na análise do questionário feito ao professor, especificamente das questões de número 3 e 4, que buscava saber se ele aplica o conhecimento da matemática envolvendo a cultura e o saber local de seus alunos e a outra questão para saber se o mesmo trabalhava com a construção de algum tipo de 
material na temática da cultura ribeirinha. Ambas as questões se destacam, sendo que a questão de número 3 o mesmo respondeu que sim e na questão de número 4 ele respondeu que não, ou seja, ele aplica o conhecimento matemático envolvendo a cultura desses alunos, mas não constrói nenhum tipo de material com eles que envolvam a cultura local. Levando em conta essas duas questões, também destacamos outras duas questões que correspondem ao questionário elaborado para os discentes.

As questões de número 4: Nas aulas de matemática são aplicados pelo professor assuntos e atividades contextualizadas relacionado ao seu dia a dia? E a de número 5: Você já construiu algum trabalho matemático envolvendo o seu cotidiano? Merecem destaque como nos mostra os resultados através do gráfico 1 e 2, a seguir:

GRÁFICO 1: Nas aulas de matemática são aplicados pelo professor assuntos e atividades contextualizadas relacionado ao seu dia a dia?

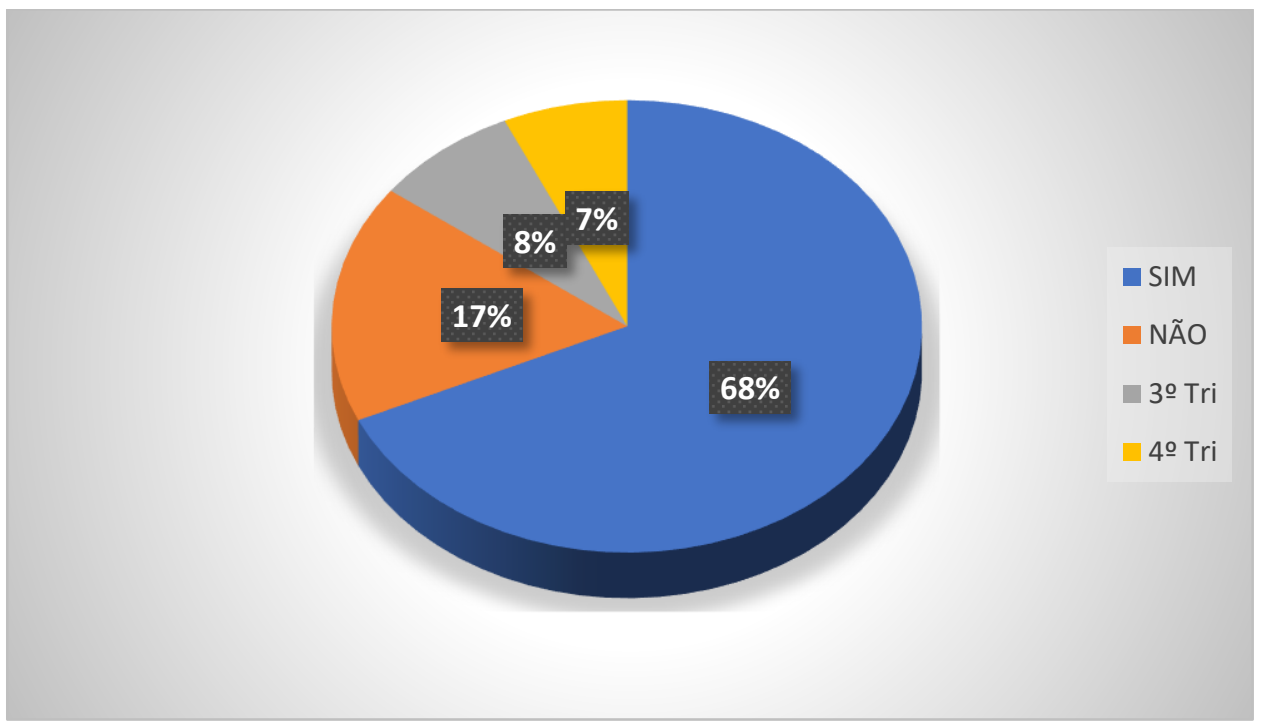

Fonte: Pesquisa de campo, 2019.

No gráfico 1 podemos perceber que 68\% dos alunos respoderam que sim, isto é, que durante todo o ano letivo o professor aplica nas aulas de matemática assuntos e atividades contextualizadas relacionadas ao seu dia a dia. No entanto, a opinião do restante dos alunos varia de acordo com o período de quando essas atividades ocontecem, pois para alguns somente no 
terceiro trimestre do ano seletivo (8\%), para outros, somente no quarto trimestre do ano letivo (7\%) e para outros, não acorrem em nenhum momento do ano letivo (17\%).

GRÁFICO 2: Você já construiu algum trabalho matemático envolvendo o seu cotidiano?

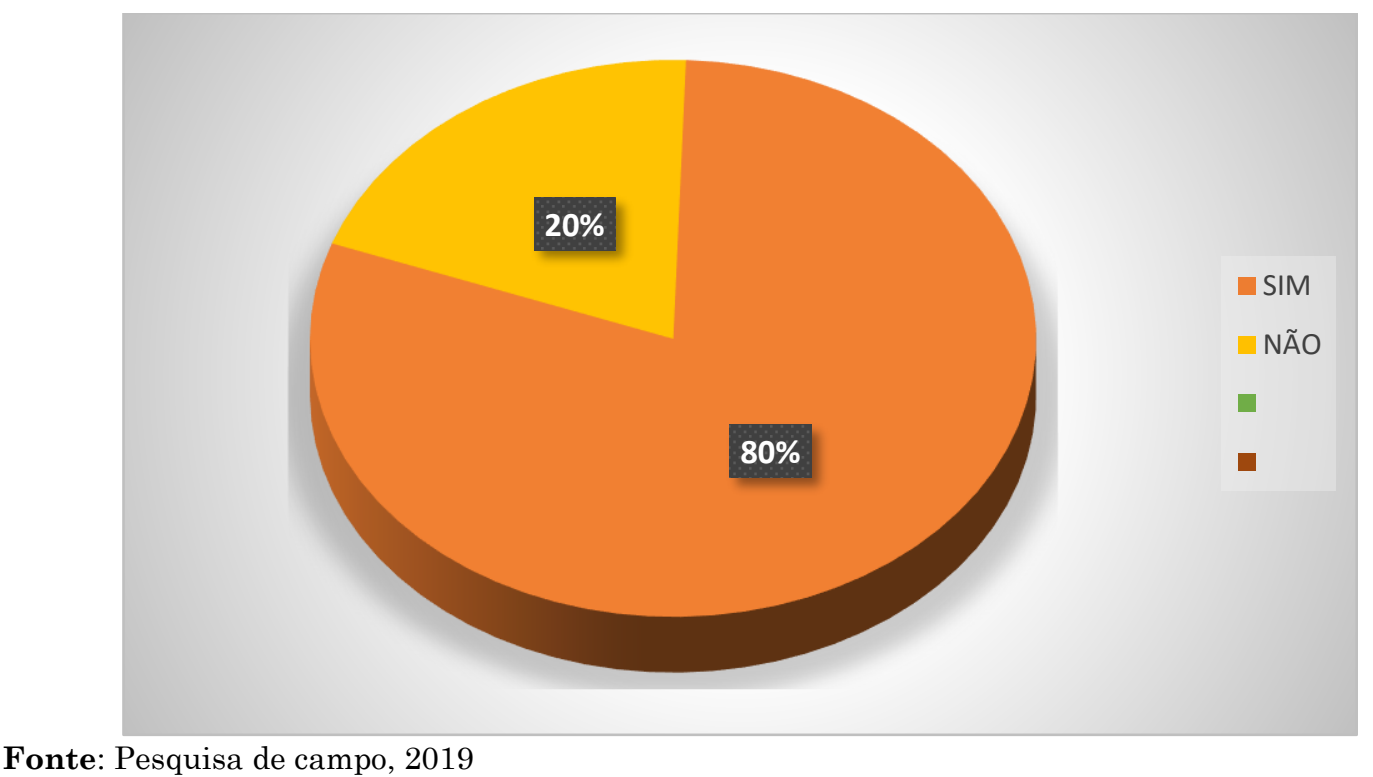

No gráfico 2, percebemos que doze alunos (80\%) respodenram que o docente aplica atividades contextualizadas envolvendo o dia a dia e três alunos (20\%) respoderam que esse professor não aplica. Através dos resultados é possível afirmar que o docente utiliza da cultura local em suas aulas de matemática e que o mesmo aproveita dos saberes matemáticos trazidos de casa pelos alunos.

Segundo D’Ambrósio (1998) as diversas tendências em educação matemática propõe um ensino-aprendizagem mais crítico e significante, evidenciando o Programa Etnomatemática, ou seja, uma das utilidades da Etnomatemática é instigar a natureza universal da matemática e mostrar diferentes pensamentos matemáticos, e com o propósito de promover o entendimento matemático para todos.

É importante destacar que a etnomatemática para os povos ribeirinhos é de muita relevância, pois são conhecimentos tradicionais, passados de 
geração em geração, conhecimentos esses que são utilizados pelos povos ribeirinhos na prática de seus trabalhos de campo, da roça, exercendo os trabalhos de forma eficiente, usufruindo de conhecimentos que exigem cálculos, noções básicas sobre matemática. Mas a grande maioria dos ribeirinhos, como se observa na Amazônia brasileira não tem uma escolarização de qualidade, mas praticam e desenvolvem suas atividades com excelência apenas com conhecimentos tradicionais.

\section{Conclusão}

Com a pesquisa é possível afirmar que a etnomatemática faz a ciência da matemática estar presente em qualquer lugar. Mesmo que esta não esteja sistematizada através de processos de escolarização formal e/ou informal, o ser humano usa o conhecimento matemático no seu cotidiano, em qualquer atividade.

Com a pesquisa é possível dizer que a etnomatemática já tem fortes argumentos para a sua existência nos pensamentos sobre o ensino da matemática. A ênfase no reconhecimento da multiplicidade metodológica e nos princípios culturais apontam o quanto a etnomatemática se encaixa a estes tempos atuais nos quais o multiculturalismo tem sido um dos focos da reflexão na Educação Matemática.

A pesquisa constatou que na Escola Estadual Levindo Alves dos Santos, especificamente na turma do $7^{\circ}$ ano do ensino fundamental, o docente utiliza da etnomatemática no ensino e aprendizagem da matemática e que esta é compreendida pelos alunos.

O contato com a realidade da turma revelou que existe a valorização da cultura local. Quanto a prática docente do ensino de matemática, o professor utiliza em sua metodologia a contextualização de atividades voltadas a realidade ribeirinha, porém não utiliza nenhum tipo de construção de trabalho junto aos alunos, mas essa falta de construção não afeta o processo de ensino e aprendizagem da turma, pois o método utilizado pelo professor é 
compreendido pela classe.

Observamos que em meio as dificuldades enfrentadas por parte dos alunos do $7^{\circ}$ ano do esino fundamental em compreender a matemática, bem como as dificuldades e desafios por parte dos profissionais que trabalham no campo e com educação ribeirinha, o docente tem procurado desempenhar uma prática diversificada que esteja ao alcance e realidade dos educandos.

Destacamos que o docente ao trabalhar a etnomatemática no espaço escolar, os alunos se sentem mais atraídos, participam mais das aulas e conseguem entender que a matemática tem relação com seu cotidiano, melhorando assim o entendimento e a aprendizagem da matemática.

\section{Referências}

BARDIN, L. Análise de conteúdo. São Paulo: Edições 70, 2011.

BRASIL. Parâmetros curriculares nacionais: matemática/ Ministério de Educação. Secretaria da Educação Fundamental. 3.ed. Brasília: A Secretaria, 2001.

BRASIL. Lei de Diretrizes e Bases da Educação Nacional. Senado Federal. 4. ed. Brasília (DF), 2007.

D’ AMBRÓSIO, U. Etnomatemática e educação. In: KNIJNIK, G.; WANDERER, F.; OLIVEIRA, C. J. (Orgs.). Etnomatemática, currículo e formação de professores. Santa Cruzdo Sul: EDUNISC, 2004. p. 10-32.

D’ AMBRÓSIO, U. Etnomatemática: Arte ou técnica de explicar ou conhecer. 5. edição. São Paulo: Ática, 1998 (Série Fundamentos).

FERREIRA, E. S. Etnomatemática: Uma Proposta Metodológica. Rio de Janeiro: MEM/USU, 1997 (Série Reflexão em Educação Matemática).

RADICCHI, R. Ensino/aprendizagem da matemática nas escolas populares. 2012.

ROSA NETO, E. Didática da Matemática. São Paulo: Ática, 1998.

SOUZA, A. B. de; CARDOSO, J. O uso da Etnomatemática como estratégia facilitadora no processo ensino aprendizagem. Pará: UEPA, 2009.

Recebido em dezembro de 2019.

Aprovado em fevereiro de 2020. 